\title{
By an eccentric whim of fate or on centralized schedule from above?
}

\section{/Introductory part/}

The freshest widely publicized successes of overseas theorists who have by guess "studied" the first seconds after the Big Bang through orbiting telescopes and nuclear colliders, along with pride in modern world science, cannot but evoke in you and me a bit of sound skepticism about their activities. For such a zero retropolation often, alas, contradicts many accepted logical postulates. In particular, if long-term forecasts are anyway built usually thanks to the sufficient availability of $100 \%$ proven archived facts, then it is still not entirely clear, what speculative "peeping" into pre-human history can be based on. Hence, one shouldn't, as it were, be extra surprised at the abundance of various false moves and other misbeliefs (like torsion fields' memorable insanity), by the spontaneous witnesses of which most of us had a chance to become. Wherein some experts frankly assess the today stalemate uncertainty as a kind of creative stagnation; second are inclined towards the version of consumerity-driven global theoretical shift; while third directly declare that it is time for representatives of the exact sciences, obviously, to prepare for the change of the old starry paradigm to cardinally updated.

So, the discussion authorial work given here casts doubt on the rightness of the Nobel Committee, which awarded its high international prize 10 years ago to a triple of American astrophysicists A.G.Riess - S.Perlmutter - B.P.Schmidt. Although let's still clarify: in this case we are not talking about a technical faults in measuring the color spectrum or luminosity of some fuzzing supernovae (which they directly dealt with), but about the subsequent too free interpretation of the results obtained, that ultimately led a general dominant influence of the term "dark energy".

However besides, this article also makes a bold desperate attempt to debunk (or, at least, a little "to ground") one more agitating human mind eternal cosmic mystery associated with the phenomenon of "magno silentium universi".

\section{/Main body/}

As firsthand confirmed by the sad experience of Carl Sagan, Seth Shostak, Jill Tarter, Victor Schwartzman, Gregory Beskin and other active SETI-researchers, all five options of the modern interpretation of "grande silentium universi", alas, may turn out to be untenable without involving a number of additional entities. So, let's briefly recall them here.

1) Life is an extremely rare phenomenon. (Parried by the data of paleocosmonautics and, in particular, the presence of bacteria in meteorites.)

2) All civilizations eventually come to hedonism. (However both the banal consumerity and the notorious hedonism can hardly be regarded in the form of some persistent attribute of public shapings: unless as a certain mediate stage in the structuring of the intelligent Universe).

3) All civilizations available today are non-technogenic. 
4) All civilizations sooner or later come to self-destruction.

5) Though life as such is widespread throughout the Space, but on a whim of fate, our civilization was the initial (or at least the second) in this "happy-scroll".

However, with the postulating an extra-material god, the 3rd and 5th versions can even so get a completely reasonable explanation here. In addition, item 5 entirely fits into the anthropogeocentric platform. And since the existence of high powers is indirectly confirmed by many other mysterious artifacts, then god-presence (in relation to i.5) can be interpreted transcendentally: say, as a manifestation of some parallel worlds or the "soft" dictate (seeming to us unobtrusive at all) of a priori sacralized Chronos i.e., to put it simply time. Let's note, by the way, the last thing is yet equivalent to the statement of overwhelming astrological dependence either. At that these are not even two sides of a single coin but in general two completely tantamount definitions of the same phenomenon. And among other things, such a qualitative converting of the dominated spatio-temporal paradigm would certainly help to deal with the notorious "dark energy", which actually does not exist at all. By the way, in more detail this will be discussed in the final section of this publication.

Thus, now the question on the immediate agenda is whether individualized high powers like UFOnauts, angels and other demigods (united - according to the author - under a common name of "pranophytes") really sit in the world. For the presence of the supreme extra-material substance doesn’t already cause, probably, any doubts: without it planetary progress would have been simply impossible. However such pranophytes can be imagined both in the kind of collection of special elementary particles and in the form of diverse wave emanations, let alone infusions of some spiritualized energy from parallel worlds. Shortly speaking, this purely outlook question is still relevant to us - despite the fact that higher superindividuals almost never interfere in everyday aspects of social life (not to mention someone's concrete human destinies).

But generally, it makes sense to talk now about 3 principled dynamic schemes of universe:

a) a kind of swing "from energy (Will) to information (Reason) and back";

b) continuous experiments or even improvisations of Will itself (by the by, the old theosophical teaching about the before predominated 5 lightly-built races also fits into here);

c) and finally, as if independently of them, a fashionable freshly-baked hypothesis about our existence as a computer simulation of the physical world can be considered either (moreover, in this case, bits and bytes well familiar to IT-specialists become already the main source of interaction of all real-virtual objects).

In the first paragraph, predicting events (proscopy) is possible due to a clear step-bystep repeatability of history; and in the second - through the management of the desirable for Will events. As for the semi-fantastic idea of parallel worlds (or, say, multidimensional space), it doesn't, apparently, jump beyond this framework but only brings some own colorful variety to the overall picture.

In this way, the ability to foresight may well not be associated with those miracles we are accustomed to (or about which, at least, have been reading more than enough). For the 
seers contemplate not the coming perspective itself, but only astral expansion somehow coupled with it (even if they borrow all the required information from celestial contactagents). This version is also confirmed by numerous cases from the life of twins which, developing from a single maternal ovum, have respectively a joint astral line (as a result of that are then subjected to almost identical vicissitudes of fate). And from this, in turn, it follows that above-mentioned metaphysical vector (or if you like - theosophical sheath) has the greatest impact on the subconscious thoughts and many involuntary movements of person.

Thus, astrology in its essence is by no means reduced to a banal copying of various Universe's cycles. But even if it can be done, then ipso facto time itself ought to have some special transcendental qualities that would determine its interest in certain objects. After all, be that as it may, any babe, apparently from conception, is already organically connected with heaven with invisible strong bonds, therefore the theosophical version of the astral as one of the influential "subtle matters" has by and large the full right to exist.

In turn, the meaningfulness or, say, spirituality of time (as if dominating over space) is just a very tempting, in principle, idea either, that saves us, by the way, from the obligatority of the astral microsphere. And nevertheless, within the framework of the author's hypothesis "Earth is the center of the Universe" (or, as an option, religious: "man is the crown of creation"), everything can already be determined by the very configuration of stellar ensembles.

It is curious that the heavens selectively show their sympathy-antipathy for specific individuals (and sometimes even for entire countries) precisely at the level of luck, or, in extreme cases, the basic vital instincts, but at all, however, do not regulate the degree of development of their mental abilities. This once again emphasizes the ancient evolutionary nature of such connections - as, incidentally, the fact that mankind is gradually getting rid of them (and in a robotic society they, apparently, will finally lose their relevance).

But still, whatever it was, knowing the results of the forecasting (whether from the mouth of a palmist, parapsychologist or even simple gypsy fortune-teller), with a strong own desire those can, of course, be prevented! Thereby, all the common pseudoscientific speculations on this theme (arbitrarily taken, for example, from biographies of Napoleon Bonaparte, queen Marie Antoinette, A.S. Pushkin, M.S. Gorbachov, Indira Gandhi, Donald Trump and others) do not have any serious evidence base.

\section{/The resumptive summary/}

So, what useful for science conclusions can be drawn from this?

Well, first of all, the old battered idea of the chrono-sacred nature of being is quite capable, obviously, to find here a new weighty portion of incentive bonuses. For in itself, the one-pointedness of the arrow of time fundamentally contradicts all our foundations of ordinary mundane logic, based, one way or another, on practically everywhere observed attributive symmetry of the type "plus-minus”, "left-right", "better-worse”, "larger-lesser”, "upward-underward”, "forward-back" (i.e. it's just as if inaccessible to meaningful human perception a priori)*.

As for the problem "grande silentio universi" that we have put into the title, the situation here requires, frankly, a special and truly serious philosophical approach. 
If, according to Drake's formula,

$$
N=R \cdot f_{p} \cdot n_{e} \cdot f_{l} \cdot f_{i} \cdot f_{c} \cdot L
$$

- there should be a dozen highly developed alien communities in the not so, seemingly, remote expanses of the Milky Way, and such, alas, are none at all, then a trite Laplacian justification doesn't work here. That is, more specifically, this may indicate one of three options:

I) the etiological complexity of the origin of civilizations associated with the nonlinearity of the paths "from inanimate $\Rightarrow$ to living" (which, as it were, is confirmed by the spread version of the five discarnate races that preceded us);

II) a certain planning of space exploration (but this obviously requires the creative participation of some almighty Scheduler!);

III) good location of our home planet near the very center of the Universe.

The first of these assumptions belongs to the theosophical school, while the second represents the canonical idea of orthodox Christianity. And only the last of the options gives a general holistic idea of a new, rather original way of settling the Fermi paradox. Moreover just in this variant, the so called mystery of dark energy (which in many respects, it turns out, is due to the spatial point of coordinates chosen by the active subject himself) can be solved without any special difficulties. For on the periphery of topologically closed Universe, an observer won't just find a single dark erg or even an extra electron-volt in this case. After all, among other things, authorial concept also unambiguously states the illusory nature of "the global acceleration" ostensibly recorded by the notorious American trinity Riess \& Perlmutter \& Schmidt.

- Although it is possible that at the micro-world level, the course of time may differ from how we perceive it in everyday realities (for example, by the partial symmetry about the reference point); but with the preservation, however, of the dominant principle of irreversibility!

Emir E. Ashursky /Kiev, Ukraine/ 